\title{
Studi Analitis Peristiwa Isra' Mi’raj Nabi Muhammad SAW dalam Pendekatan Sains
}

\author{
Fatoni Achmad \& Ivonia \\ Universitas Negeri Jenderal Soedirman Purwokerto \\ Email: noemail@gmail.com
}

\begin{abstract}
About 1400 years ago, we heard of a great event from the Arab land, Isra 'Mi'raj. However, over time, and the times are getting better with increasing science theory. Then the events of Isra and Mi'raj can be revealed in modern physics so that they can be accepted by human reason. Through Einstein's theory of relativity, $\mathrm{E}=\mathrm{m} . \mathrm{c} 2$ (where $\mathrm{E}$ is energy, $\mathrm{m}$ is mass, and $\mathrm{c}$ is the speed of light), Isra 'Mi'raj becomes an event that is no longer irrational, but rational and scientific. Then, on what part of the theory of relativity play a role in explaining the events of Isra 'and Mi'raj of the Prophet Muhammad SAW scientifically? All will be explored comprehensively and systematically in this paper.
\end{abstract}

Key Word: Isra' Mi'raj, Science Approach, Theory of Relativity

\section{A. Pendahuluan}

Allah Subhanahu Wata'ala Ialah Dzat sebaik-baiknya pencipta seluruh alam semesta dan isinya. Salah satu makhluk yang sebaik-baik diciptakanolehNya, berakal, serta dimuliakan kedudukannya, dan makhluk tersebut adalah manusia. Walaupun manusia adalah sebaikbaiknya makhluk yang pada dasarnya merupakan makhluk yang lemah dan punya keterbatasan dalam hal apapun serta dapat menelaah bahkan berfikir lebih kompleks sehingga dapat menciptakan suatu perkembangan teknologi dalam waktu yang bersamaan.

Jika dikaitkan dengan persoalan ilmu agama dengan ilmu sains, seiring dengan perkembangan zaman dan peningkatan sumber daya 
manusianya yang tinggi, peristiwa yang tercatat dalam firman-Nya dan sebagai mukjizat yang turun langsung perintahnya dari sang pencipta kepada Nabi Muhammad Shallallaahu 'alaihi wassalam untuk melakukan perjalanan mengelilingi seantero jagat raya. Sekitar 1400 tahun yang lalu, kita mendengar suatu peristiwa yang maha hebat dari tanah Arab. Peristiwa yang jauh lebih mengagumkan dari satelit ataupun sputik dan benda langit lainnya. Peristiwa yang dikenal dengan nama Isra' Mi'raj. dimana pada peristiwa ini turun perintah untuk shalat lima waktu. Pada saat itu, keadaan Nabi Muhammad sedang sangat terpukul dengan wafatnya istri tercinta Siti Khadijah r.a. Kaum Quraisy yang mengetahui kelemahan dakwah nya Nabi yaitu dengan senantiasa selalu mengusik keluarga Nabi Muhammad terlebih lagi ketika pamannya telah wafat. Dalam kondisi yang seperti itu, kemudian Allah mengundang Nabi Shallallaahu 'alaihi wassalam melalui peristiwa Isra' Mi'raj.

Allah mengirimkan Jibril untuk datang menemui Muhammad dan menyampaikan perintah Allah bahwa ia disuruh untuk mengajak Rasulullah Shallallahu 'alaihi wassalam melakukan perjalanan Isra' Mi'raj. sebagaimana yang dijelaskan dalam firman Allah pada Al Qur'an surah AnNajm ayat 13-18 yang artinya "Sesungguhnya ia (Muhammad) melihat Jibril (dalam rupanya yang asli) di waktu yang lain. Yaitu di Sidratul Muntaha. Di dekatnya ada surga tempat tinggal. (Muhammad melihat Jibril) ketika Sidratul Muntaha itu diliputi oleh sesuatu yang mrliputinya. Penglihatannya (Muhammad) tidak berpaling dari yang dilihatnya itu dan tidak (pula) melampauinya. Sungguh ia telah melihat sebagian tanda-tanda (kekuasaan) Tuhannya yang paling besar."

Lalu Jibril mendekati Nabi Muhammad Shallallahu 'alaihi wassalam dan menyampaikan perntah dari Allah, bahwa ia disuruh melakukan perjalanan Isra' Mi'raj. sebelum melakukan perjalanan, Jibril membersihkan hati Nabi terlebih dahulu dengan air zam-zam sebagai persiapan melakukan perjalanan ini. Setelah melakukan segala segala 
persiapannya, maka dibawalah Nabi dengan mengendarai Buraq. Buraq yang berasal dari kata Barqum yang artinya kilat, menuju Masjidil Haram ke Baitul Maqdis yang berjarak $1500 \mathrm{~km}$ dari Mekkah. Mereka menempuh pejalanan yang sangat jauh dan itu hanya memakan waktu setengah malam, atau bahakan lebih singkat lagi. ${ }^{1}$

Setelah Rasulullah menyelesaikan seluruh perjalanannya, Rasulullah tiba kembali di tengah kaumnya, beliau menceritakan kepada mereka tanda-tanda kekuasaan terbesar yang diperlihatkan oleh Allah kepadanya. Lalu perihal waktu perjalanan yang singkat, padahal jarak yang sangat jauh namun dapat ditempuh hanya waktu setengah malam dan juga Rasulullah kembali dengan keadaan sehat, jiwa dan raganya masih utuh itu menimbulkan doktrin permasalahan yang kontroversial. Dimana ada hal yang sangat mustahil untuk dilakukan oleh manusia pada umumnya. Justru bagi mereka (kaum Rasulullah SAW) bertambah tidak mempercayai beliau, dan terlebih lagi, mereka mengganggu beliau karena beliau sangat nekat.

Namun, seiring dengan berjalannya waktu, dan zaman semakin membaik dengan meningkatnya teori sains. Maka peristiwa Isra' dan Mi'raj dapat diungkap dalam ilmu fisika modern agar dapat diterima oleh akal manusia.

\section{B. Metode}

Pendekatan penelitian yang digunakan adalah pendekatan kualitatif. ${ }^{2}$ Sedangkan jenis penelitian dalam penelitian ini menggunakan jenis penelitian kepustakaan atau library research. ${ }^{3}$

\footnotetext{
${ }^{1}$ Agus Mustofa. Terpesona di Sidratul Muntaha. (Surabaya: Padma, 2006), hal. 19

${ }^{2}$ yaitu penelitian yang datanya dinyatakan dalam keadaan sewajarnya atau apa adanya (naturalistik, natural setting), tidak dirubah dalam bentuk simbol-simbol atau bilangan dengan maksud untuk menemukan kebenaran dibalik data yang objektif dan cukup lihat Mundir, Metode Penelitian Kualititatif \& Kuantitatif, (Jember: Stain Jember Press, 2013),. 51.

${ }^{3}$ Penelitian kepustakaan adalah penelitian yang dikerjakan untuk memecahkan suatu masalah yang bertumpu pada studi kritis terhadap bahan- 
Di dalam literatur lain ${ }^{4}$ (library research), yaitu penelitian yang dilaksanakan dengan menggunakan literatur (kepustakaan), baik barupa buku, catatan, maupun laporan hasil penelitian terdahulu. ${ }^{5}$ Kajian pustaka juga diartikan proses umum yang dilakukan peneliti dalam upaya menemukan teori. $^{6}$

Secara hakikat data yang diperoleh dengan penelitian perpustakaan ini dapat dijadikan landasan dasar dan alat utama bagi pelaksanaan penelitian. ${ }^{7}$ Maksud peneliti adalah dengan menggunakan penelitian perpustakaan dapat memberi informasi atas segala yang berhubungan dengan Peristiwa Isra’ wal Mi’raj.

\section{Hasil dan Diskusi}

\section{Ruang Lingkup dan Gambaran Umum}

Peristiwa Isra' Mi'raj pada dasarnya adalah dua peristiwa yang berbeda. Hanya saja peristiwa Isra' yang terjadi dalam satu malam dengan peristiwa Mi'raj. Namun, masyarakat sekitar menganggapnya sebagai peristiwa yang sama dengan menggabungkan dua kata, yaitu Isra' Mi'raj.

Isra' secara bahasa berasal dari kata saro' yang bermakna di malam hari, adapun secara istilah Isra' berarti perjalanan Rasulullah shallallahu 'alaihi wassalam bersama jibril dari Mekkah ke Baitul Maqdis dengan mengendarai Buraq dengan waktu yag relatif

bahan pustaka dan hasil penelitian terkait yang disajikan dengan cara baru, lihat Padmo Sukoco, Penelitian Kualitatif: Metodologi, Aplikasi, dan Evaluasi, (Jakarta: Gunung Agung, 2002), 209.

${ }^{4}$ Kajian pustaka pada umumnya menggunakan metode pendekatan kualititatif, sebagai prosedur penelitian, metode ini menghasilkan data deskriptif berupa kata-kata tertulis atau lisan. Lihat Marzuki, Metodologi Riset, (Yogyakarta: Ekonisia, 2005), 14.

${ }^{5}$ Sangadji, Metodologi Penelitian Pendekatan Praktis dalam Penelitian, 28. Untuk lebih mempermudah dalam memahami, penelitan pustaka (library research) adalah penelitian yang digolongkan menurut tempat penelitian itu dilaksanakan. Mardalis, Metode Penelitian Suatu Pendekatan Proposal, 28

${ }^{6}$ Mundir, Metode Penelitian Kualititatif \& Kuantitatif, 140.

${ }^{7}$ Mardalis, Metode Penelitian Suatu Pendekatan Proposal, (Jakarta: PT Bumi Aksara, 2009)., 28 
singkat. ${ }^{8}$ Perjalanan ini bisa disebut perjalanan horizontal karena Nabi masih berada di bumi. Sebagaimana pada firman Allah dalam surah Al Isra ayat satu, yaitu :

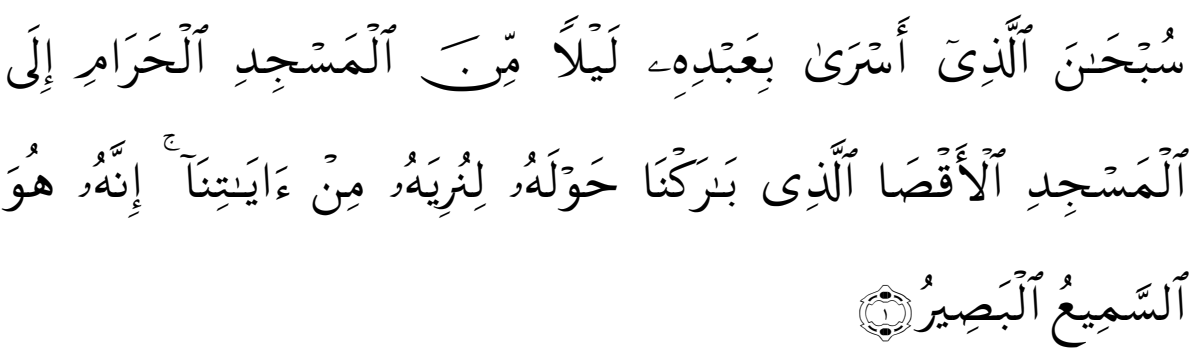

"Maha suci Allah, yang telah memeperjalankan hambaNyapada suatu malam dari Al Masjidil Haram ke Masjidil Aqsha yang telah Kami berkahi sekelilingnya agar Kami perlihatkan kepadanya sebagian dari tanda-tanda (kebesaran) Kami. Sesungguhnya Dia adalah Maha Mendengar lagi Maha Mengetahui.” (Q.S. Al Israa' :1)

Mi'raj secara bahasa adalah suatu alat yang dipakai untuk naik, adapun secara istilah, Mi'raj bermakna tangga khusus yang digunakan oleh Nabi untuk naik dari bumi menuju ke atas langit, yaitu langit ke tujuh $^{10}$ hingga ke Sidratul Muntaha yang secara harfiah berarti 'tumbuhan sidrah yang tak terlampaui. ${ }^{11}$ Dimana tempat tersebut tidak ada ada yang dapat melampaui dan mengetahaui lebih banyak mengenai tempat itu'. Yaitu perjalanan dari Masjidil Aqsha di Palestina lalu naik ke luar angkasa melalui beberapa tingkatan langit, lalu menuju ke Baitul Makmur, hingga sampai di Sidratul Muntaha, Arsy (Takhta Tuhan) dan saat itu beliau mendapatkan perintah untuk

${ }^{8}$ Syaikh Shafiyurahman Al-Mubarakfuri, Sirah Nabi, (Bandung: PT Mizan Pustaka,2012), hal.126.

${ }^{9}$ Q.S. Al Isra' Ayat 1 Al Quran Al Karim, (Jakarta Penerbit C.V. Pustaka Amani, 2006), hal. 225.

${ }^{10}$ Lihat Syarh Lum'atil I'tiqaad Li Syaikh Ibnu 'Utsaimin hal. 58 - 59.

${ }^{11}$ Muhammad Al-Ghazali, Sejarah Perjalanan Hidup Muhammad, ( Yogyakarta: Mitra Pustaka,cet.3, 2005), hal. 157. 
mendirikan shalat lima waktu sehari. ${ }^{12}$ Berdasarkan pada firman Allah pada Surah An Najm ayat 13-18, yaitu :

"Dan sesungguhnya Muhammad telah melihat Jibril itu (dalam rupanya yang asli) pada waktu yang lain, (yaitu) di Sidratul Muntaha. Di dekatnya ada surga tempat tinggal, (Muhammad melihat Jibril) ketika Sidratul Muntaha diliputi oleh sesuatu yang meliputinya. Penglihatannya (Muhammad) tidak berpaling dari yang dilihatnya itu dan tidak (pula) melampauinya. Sesungguhnya dia telah mellihat sebahagian tanda-tanda (kekuasaan) Tuhannya yang paling besar." (Q.S. AnNajm : 13-18)

Peristiwa maha dahsyat ini beracuan pada Al Qur'an Surah AlIsraa' ayat satu yang artinya :

"Maha suci Allah, yang telah memeperjalankan hambaNya pada suatu malam dari Al Masjidil Haram ke Masjidil Aqsha yang telah Kami berkahi sekelilingnya agar Kami perlihatkan kepadanya sebagian dari tanda-tanda (kebesaran) Kami. Sesumgguhnya Dia adalah Maha Mendengar lagi Maha Mengetahui."

Di dalam ayat ini, Allah menjelaskan secara singkat mengenai skenario perjalanan Isra' Mi'raj Nabi Muhammad shallallaahu 'alaihi wassalam yang hanya ditumpuh dalam waktu satu malam.Namun jika dilihat dari kandungan surat Al Isra'menunjukkan bahwa peristiwa Isra' Mi'raj terjadi pada masa-masa akhir sebelum hijrah. ${ }^{13}$ Sehingga dengan ayat ini kita dapat lebih mudah mendapat pemahaman tentang mukjizat yang diberikan oleh Allah untuk hambaNya yaitu peristiwa Isra' Mi'raj. Namun, Allah juga berfirman dalam Al Qur'an surah An Najm ayat 13-18 mengenai perjalanan Isra' Mi'raj. Sebagaimana artinya menyebutkan bahwa :

"Dan sesungguhnya Muhammad telah melihat Jibril itu (dalam rupanya yang asli) pada waktu yang lain, (yaitu) di Sidratul Muntaha. Di dekatnya ada surga tempat tinggal, (Muhammad melihat Jibril) ketika Sidratul Muntaha diliputi oleh sesuatu yang meliputinya. Penglihatannya (Muhammad) tidak berpaling dari yang dilihatnya itu dan tidak (pula) melampauinya. Sesungguhnya dia telah mellihat sebahagian tanda-tanda (kekuasaan) Tuhannya yang paling besar.” (Q.S. AnNajm : 13-18)

233.

${ }^{12}$ Ali, Yunasril. Ensiklopedia Islam. (Jakarta: Ichtiar Baru Van Hoeve, 2005), hal.

${ }^{13}$ Shafiyyurrahman Al-Mubarakfury, Ar-Rakhiq Al-Makhtum, (Al-Manshurah: Dar Al-Wafa, 2002), hal. 160. 
Setelah melihat kisah Isra' Mi'raj dari segi perkataan maupun firman Allah, namun, ada pula rincian dan urutan kejadian mengenai peristiwa Isra' Mi'raj ini dalam hadits yang shahih dengan berbagai riwayat. Di antara banyak hadits shahih tersebut yang menceritakan kejadian Isra' Mi'raj ini adalah hadits yang diriwayatkan oleh Imam Muslim dalam keshahihannya.

Dari Anas Bin MalikRadhiyallaahu anhu bahwa Rasulullah shallallahu 'alaihi wassalam bersbada. Pada waktu itu, Nabi Muhammad shallallahu 'alaihi wasaalam sedang berbaring tidur bersama dua orang laki laki (Hamzah bin Abdul Mutthalib dan Ja'far bin bin Abi Tholib) di Hijr Ismail samping Ka'bah, maka datanglah Jibril dan Mikail serta bersamanya malaikat lain yaitu Israfil. Lalu para malaikat membawa Nabi Muhammad shallallaahu 'alaihi wassalam ke sumur zam-zam dan melentangkannya. Dan pada waktu itu, sesi ini yang lebih berperan adalah malaikat Jibril. Lalu Jibril membelah bagian atas dada Nabi, hingga bawah perutnya, dikeluarkannya hatinya dan membasuhnya hingga tiga kali dengan semangkuk air zam-zam serta membersihkan apapun yang mengganggu hatinya. Setelah semua selesai dibersihkan, Malaikat Mikail membawakan lagi satu mangkuk yang terbuat dari emas dan dipenuhi oleh hikmah iman lalu menuangkannya ke dada Nabi Muhammad shallallahu 'alaihi wassalam. Dengan penuh kebijaksanaan, keilmuan dan keyakinan dalam islam, rapatlah kembali dada Nabi Muhammad shallallahu 'alaihi wassalam dan memberikan tanda dengan tanda nubuwah ${ }^{14}$.

Setelah dibersihkan seluruh hatinya, didatangkan buroq yang indah dan bertali kekang. Buroq adalah hewan yang berwarna putih, lebih tinggi dari keledai serta lebih kecil dari baghal (hasil perkawinan antara kuda dan keledai). Langkahnya sejauh mata Nabi memandang,

\footnotetext{
${ }^{14}$ Muhammad Al-Ghazali, Sejarah Perjalanan Hidup Muhammad, ( Yogyakarta: Mitra Pustaka, cet.3, 2005), hal. 159. 
memiliki dua telinga yang panjang. Apabila mendaki gunung maka maka terangkat lebih tinggi kaki depannya. Buroq memiliki dua sayap di bagian pinggulnya yang mana berfungsi untuk membantu kakinya agar lebih cepat. Pada awalnya, ketika Rasulullah shallallalhu 'alaihi wassalam ingin menaikinya, Buroq memberontak. Lalu Jibril meletakan tanganya di ata kepalanya, seraya berkata "tidakkah kau malu wahai buraq! Demi Allah tidak ada makhluk yang lebih mulia darinya yang telah menaikimu.” Langsunglah Buraq merasa malu dan dengan tenang dan senantias segera dinaiki oleh Rasulullah shallallahu 'alaihi wassalam. Sebelumnya, Buraq juga merupakan kendaraan para anbiya sebelum Rasul.

Setelah menungganginya, Rasulullah shallallahu 'alaihi wassalam dan Jibril segera memulai perjalanannya menuju Masjidil Aqsha. Setelah sampai di Baitul Maqdis, Nabi Muhammad shallallahu 'alaihi diperintahkan oleh Jibril untuk melakukan shalat dua rakaat. Setelah selesai shalat, Jibril 'alaihi salaam datang kepadanya dengan membawa bejana berisi khmar dan bejana berisi air susu. Dan Nabi memilih bejana yang berisi air susu. Jibril kemudian berkata, "Engkau telah memilih (yang sesuai) fitrah. Seandainya engkau memiliih khmar, niscaya sesatlah umatmu." Sampai di sini lah berakhirnya perjalanan Isra' Nabi Muhammad shallallahu 'alaihi wassalam, di permukaan bumi.

Setelah itu, berangkatlah Jibril dan Nabi Muhammad shallallahu 'alaihi wasaalam dengan mengendarai buraq naik ke langit terendah, atau bisa disebut langit dunia. Kemudian Jibril minta dibukakan pintu, maka dikatakan (kepadanya), “siapa engkau?” Dia menjawab, "Jibril". Lalu bertanya lagi, "siapa yang sedang bersamamu?" Dia menjawab, "Muhammad", dan dikatakannya lagi, "apakah dia telah diutus?" lalu Jibril menjawab "Dia telah diutus". Maka, setelah percakapan tadi dibukakanlah pintu langit dan Nabi 
Muhammad shallallahu 'alaihi wassalam pun bertemu dengan Nabi Adam as, lalu Nabi Muhammad shallallahu 'alaihi wassalam senantiasa mengucapkan salam kepadanya, dan Beliau (Nabi Adam) menjawabnya dan mendo'akan yang baik untuk Nabi Muhammad dan Jibril.

Lalu, ketika dilangit pertama yaitu langit dunia sebagaimana menurut hadits shahih bahwa tiba-tiba Nabi Muhammad shallallahu 'alaihi wassalammelihat secara samar wujud berwarna hitam yang ada di sebelah kanan dan kiri tempat duduk Nabi Adam AS. Apabila melihat ke sebelah kanan, Nabi Adam AS tertawa karena di dalamnya adalah orang-orang ahli surga. Namun apabila Nabi Adam AS melihat ke sebelah kiri, ia akan tempak bersedih, bahkan menangis karena di dalamnya adalah orang-orang ahli neraka.

Kemudian, setelah langit pertama (langit dunia) telah dilewati, malaikat Jibril dan Rasulullah shallallahu 'alaihi wassalam segera melanjutkan perjalanannya yaitu naik ke langit ke dua. Di langit ke dua ini, disambut sama dengan langit pertama. Jibril ditanyakan kembali mengenai siapa dia, membawa siapa dia ke langit, dan apa beliau (Muhammad shallallahu 'alaihi wassalam) telah diutus untuk ke langit. Di langit kedua ini, Nabi Muhammad shallallahu 'alaihi wassalam bertemu dengan Nabi Isa AS dan Nabi Yahya AS. Sama seperti langit pertama, Nabi Muhammad shallallahu 'alaihi wassalam segera mengucapkan salam kepada keduanya. Keduanya pun menjawabnya dengan baik dan rasa hormat tentunya. Mereka pun tak lupa mendoakan Nabi Muhammad shallallahu 'alaihi wassalam.

Setelah selesai pada langit ke dua, Nabi Muhammad shallallahu 'alaihi wassalam dan Jibril bergegas menuju langit ketiga. Di langit ke tiga ini, disambut sama dengan langit pertama. Jibril ditanyakan kembali mengenai siapa dia, membawa siapa dia ke langit, dan apa beliau (Muhammad shallallahu 'alaihi wassalam) telah diutus 
untuk ke langit. Lalu, di sini Nabi Muhammad shallallahu 'alaihi wassalam bertemu dengan Nabi Yusuf. Sama seperti langit pertama dan kedua, Nabi Muhammad shallallahu 'alaihi wassalam segera mengucapkan salam kepada Nabi Yusuf AS. Salamnya pun dijawab dengan baik dan tanpa mengurangi rasa hormat tentunya. Nabi Yusuf pun tak lupa mendoakan Nabi Muhammad shallallahu 'alaihi wassalam. Keadaan seperti ini terjadi berulang kali hingga Nabi Muhammad shallallahu 'alaihi wassalam sampai pada langit ke tujuh. Dilangit keempat beliau bertemu dengan Nabi Idris AS, dilangit kelima bertemu dengan Nabi Harum AS, dilangit keenam bertemu dnegan Nabi Musa AS, dan di langit ketujuh beliau bertemu dengan Nabi Ibrahim AS yang sedang bersandar di Baitul Makmur.

Setelah sampai pada langit ketujuh, Nabi Muhammad shallallahu 'alaihi wassalam bersama Nabi Ibrahim pergi ke Sidratul Muntaha. Di mana tempat tersebut tidak ada yang bisa menggambarkan betapa indahnya disana, yaitu sebuah pohon besar yang rindang, buahnya besar dan daun-daunnya seperti telinga gajah. Di Sidratul Muntaha juga terdapat empat sungai yang mengalir dengan dua sungai yang tampak nyata dan dua sungai lainnya yang tampak nyata. Adapun sungai yang tidak nampak nyata adalah dua sungai di syurga, sedangkan yang tampak nyata adalah sungai Nil dan sungai Eufrat. Nabi Muhammad shallallahu 'alaihi wassalam pun juga diperlihatkan Baitul Makmur yaitu rumah yang setiap harinya dimasuki oleh tujuh puluh ribu malaikat.

Di Sidratul Muntaha, Nabi Muhammad shallallahu 'alaihi wassalam meninggalkan Jibril dan segera berangkat ke Mustawa, ke hadirat Allah subhaanahu wata'ala. Di hadirat Allah subhanaahu wata'ala Nabi menerima wahyu kewajiban shalat lima puluh kali sehari semalam. Kemudian Nabi turun menemui Musa AS dan mengatakan bahwa Allah mewajibkan lima pulih kali shalat pada 
umat Nabi Muhammad. Nabi Musa pun menyarankan agar mengurangi kewajiban shalat karena sesungguhnya umat Nabi Muhammad mempunyai kemampuan yang terbatas. Setelah itu, Nabi Muhammad pun kembali kepada Allah dan memohon agar dikurangi kewajiban yang telah diberikanNya, maka Allah subhaanahu wata'ala pun mengurangi lima shalat untuk umat Nabi Muhammad shallallahu 'alaihi wassalam. Kemudian Nabi Muhammad pun turun kembali dan mengatakan kembali apa yang telah diwajibkan yaitu Allah mengurangi lima shalat dari lima puluh shalat. Namun Nabi Musa AS pun menyarankan kembali agar dikurangi jumlah shalatnya. Maka terjadilah Nabi Muhammad shallallahu 'alaihi wassalam pulang balik anatara Allah dan Musa, sampai pada akhirnya Allah pun berfirman, "Wahai Muhammad, sesungguhnya ini adalah lima shalat sehari semalam, setiap shalat (pahalanya) sepuluh, maka semuanya lima puluh shalat. Barangsiapa yang meniatkan kejelekan lalu dia tidak mengerjakannya, maka tidak ditulis (baginya) sedikitpun. Jika dia mengerjakannya, maka ditulis (baginya) satu kejelekan”. Kemudian Nabi Muhammad pun turun dan menemui Musa AS seraya menceritakan apa yang telah terjadi di atas sana. Lalu Nabi Musa pun tetap berkata untuk kembalilah kepada tuhanmu dan mintalah keringanan, namun Nabi Muhammad segera menolaknya karena dirinya telah kembali dan sampai merasa malu kepada tuhannya. (H.R. Muslim 62). ${ }^{15}$

\section{Studi Analitis Peristiwa Isra' Mi'raj Nabi Dalam Persepktif} Fisika

Fisika adalah ilmu yang mempelajari tentang alam semesta dan isinya. Gejala alam yang hidup maupun yang tidak hidup. Bahkan ilmu eksak dunia ini pun mempelajari tentang materi sekecil partikel atau elektron yang keberadaannya jelas ada namun tidak dapat dilihat

${ }^{15}$ Katsir, Ibnu. Sejarah Nabi Muhammad. (Solo: At - Tibyan, 2004), hal. 37 - 45. 
dengan kasat mata dan dapat dipelajari dalam lingkup ruang dan waktu. Ilmu fisika tidak lain disebut ilmu yang paling mendasar. Karena pada setiap ilmu alam lainnya, kurang lebih mempelajari berbagai jenis sistem materi tertentu yang mematuhi hukum fisika.

Dalam perkembangannya, ilmu fisika telah dipelajari dan dikembangkan pertama kali pada 2400 SM, pada saat itu kebudayaan Harapan menggunakan suatu benda untuk menghitung dan memperkirakan sudut bintang di angkasa. Sejak adanya hal tersebut, perlahan-lahan ilmu eksak yang satu ini berkembang menimbulkan banyak fisikawan untuk menggali lebih dalam mengenai percobaan sederhana tadi. Perkembangan ilmu fisika tidak hanya terpaut oleh perubahan benda, matematika, atau pun seperti gejala alam lainnya, namun perkembangan teknologi juga sangat mempengaruhi untuk dunia pada era berikutnya. Perkembangan Ilmu fisika dimulai sekitar tahun 1600 dan pada tahun inilah menjadi batas pemikiran antara zaman klasik menjadi zaman modern. Perkembangan untuk memulainya fisika modern pun dimulai pada tahun 1900 dan pada tahun inilah pertanda bahwa era modern atau era fisika modern telah dimulai.

Pada awalanya, menurut Richmeyer sejarah pekembanagn ilmu fisika dibagi dalam empat periode. Dimana pada periode pertama, diawali dari zaman yang sangat kuno atau biasa disebut zaman prasejarah sampai pada tahun sekitar 1550. Pada zaman ini belum terdapat penelitian yang sangat sistematis. Pada periode ini hanya mendapatkan fakta fisis yang dibutuhkan untuk perumusn empirik. Beberapa penemuan yang dihasilkan pada periode ini di antaranya seperti, penemuan bahwa satu tahun adalah 365 hari, peleburan logam, pengukuran mata uang. Serta terkait dengan hukumhukum fisika seperti hukum hidrostatika, kemagnetan, optik, bahkan ilmu matematika dan ilmu kimia juga ikut berkembang. Pada 
penghujung tahun $1550 \mathrm{M}$, Copernicus mengemukakan teori heliosentrisnya yang menjadi titik penting dalam revolusi saintifik. Dilanjut pada periode kedua, dimulai sekitar tahun 1550 hingga tahun 1800. Dalam periode kedua ini, semakin banyak teori maupun asasasas yang ditemukan oleh sang fisikawan. Di antaranya Galileo membuktikan dinamika mekanik, hukum inert juga Sir Isaac Newton yang sampai saat ini penemuannya sangat sukses yaitu Hukum gerak Newton, Hukum Gravitasi Newton. Tidak lama kemudian muncullah persamaan Bernoulli, Teori Kinetik Gas, Momentum Sudut serta mengenai panas dalam fisika ditemukannya termometer, Azaz Black, dan kalorimeternya. Dalam periode kedua ini sangat berkembang ilmu fisika yang sampai pada saat ini masih dipelajari. Pada perode ketiga dimulai sekitar tauh 1800 hingga 1900 M. Pada periode ini lah konsep-konsep fisika yang mendasar sehingga disebut fisika klasik. Fisika klasik sangat berkembang pesat dan banyak mendapatkan formula-formula umum dalam Mekanika, Panas, hubungan listrik dan magnet, serta gelombang.

Setelah melewati tiga periode yang sangat membanggakan tersebut, tibalah di periode ke empat, periode dimana fisika klasik dikembangkan lebih lanjut pada tahun 1980. Bisa dikatakan bahwa tahun tersebut adalah peralihan antara fisika klasik berakhir dan dilanjut kembali dengan sebutan fisika modern. Pada akhir abad 19 ditemukan beberapa fenomena yang tidak bisa diselesaikan oleh fisika klasik. ${ }^{16}$ Jika dikaitkan dengan peristiwa Isra' Mi’raj, pada abad inilah berbagai teori mengenai masalah kecepatan yang sangat tinggi (relativitas) atau teori yang berkaitan dengan transformasi energi pada periode ini sedang gencar diteliti lebih lanjut. Tentunya dengan adanya perkembangan ilmu fisika sangat memudahkan para peneliti

\footnotetext{
${ }^{16}$ Anonim. 2013. Periode Sejarah Fisika Menuju Era Modern. [on line]Tersedia: http://nisyadiaries28.blogspot.com/2013/04/4-periode-sejarah-fisika-menuju-era.html. Januari 2018)
} 
atau fisikawan sekali pun untuk membuktikan peristiwa Isra' Mi'raj secara ilmiah.

Teori relativitas yang dipelopori oleh Einsten menghasilkan berbagai macam konsep, di antarnya yang paling dikenal adalah konsep kesetaraan massa dengan energi, yang mana di dalam persamaan seperti:

$$
\mathrm{E}=\mathrm{m} \cdot \mathrm{c}^{2}
$$

Dimana $\mathrm{E}$ adalah energi, $\mathrm{m}$ adalah massa, dan $\mathrm{c}$ adalah kecepatan cahaya. Persamaan ini dipakai sebagai salah satu prinsip dasar dalam transformasi partikel. Transformasi atau perubahan energi menjadi materi dan sebaliknya. Hal ini terjadi karena antara energi dan materi bersifat setara dan komplementer.

Selain teori relativitas, yang pertama mengemukakan pendapat bahwa setiap gerak adalah relatif terhadap kerangka acuan khusus yang bukan merupakan kerangka acuan universal yaitu eksperimen Michaelson-Morley. Mereka berusaha untuk mengukur kecepatan planet bumi terhadap eter yang pada waktu itu dianggap sebagai medium perambatan gelombang cahaya. Hasil eksperimennya pun gagal yang berarti tidak nampak pergerakan bumi terhadap eter. Setelah itu, hasil dari percobaan Michaelson-Morley terungkap Albert Einstein, tepat pada tahun 1905 menerbitkan teori relativitas khususnya. Kata sifat khususnya ini berarti bahwa teori itu hanya berhubungan dengan kerangka acuan inersia (lembam), yaitu kerangka acuan dimana hukum Newton berlaku. Pada awalanya Albert Einstein menjadikan eksperimen yang pada dasarnya membandingkan kelajuan cahaya sejajar dan tegak lurus pada gerak bumi mengelilingi matahari, dan eksperimen ini memperlihatkan bahwa kelajuan cahaya sama bagi setiap pengamat untuk dasar bagi teori relativitas khususnya. ${ }^{17}$ Anggapan atau asumsi seperti ini sangat sulit diterima pada saat itu,

${ }^{17}$ Halliday, Resnick, dkk. Fisika Dasar Jilid III. (Jakarta: Erlangga, 2010), hal.2 - 4. 
dan tak lama kemudian Einstein mengklaim bahwa gagasan yang terdahulu mengenai relativitas khusus nya itu salah.

Namun, Relativitas Einstein pun lambat laun menjadi benar adanya untuk semua kecepatan yang mungkin memprediksi banyak efek pada kajian pertamanya, memang tampak aneh karena tidak ada yang pernah mengalaminya. Seperti itulah gambaran awal mengenai sejarah teori relativitas. Namun, sejak keluarnya teori relativitas para ilmuwan pun juga banyak menemukan inovasi terbaru terhadap perkembangan teknologi dan energi pada saat abad ke 19 itu. Seperti halnya ketika periode fisika klasik, tentang elektrodinamika klasik tanpa relativitas memperkirakan bahwa kecepatan cahaya adalah relatif konstan dengan Luminiferous aether, memang pada zaman klasik hal seperti masih sulit untuk dikembangkan lebih lanjut.

Penemuan-penemuan lain pada abad ini terus berkembang. Pada tahun 1900, Max Planck memperkenalkan ide bahwa energi dapat dibagi menjadi beberpa paket. Secara khusus ini digunakan untuk menjelaskan intensitas radiasi yang dipancarkan oleh benda hitam. Lalu selain teori relativitas Einsten, pada tahun 1905 Albert Einsten juga menjelaskan tentang efek fotolistrik dengan menyimpulkan bahwa energi cahaya datang dalam bentuk kuanta yang disebut foton. Pada tahun 1913, Niels Bohr menjelaskan garis spektrum dari atom hidrogen dan pada tahun 1934, Louis de Broglie memberikan teorinya tentang gelombang pada benda. Seperti itulah perkembangan pada periode keempat yang ilmunya sampai saat ini masih digunakan dalam pembelajaran fisika.

Sebelum membahas lebih jauh mengenai peninjauan ilmiah peristiwa Isra' Mi'raj, jika dijelaskan secara singkat mengenai Isra' Mi'raj dalam perspektif fisika modern, peristiwa ini diawali dengan datangnya malaikat Jibril kepada Rasulullah shallallahu 'alaihi wassalam yang pada dasarnya malaikat Jibril merupakan makhluk 
cahaya (dengan energi cahaya) menampakkan dirinya dengan (bertransformasi menjadi makhluk yang memiliki massa). Fenomena ini merujuk pada persamaan Albert Einstein mengenai kesetaraan massa dan energi. Dimana perubahan energi menjadi materi atau sebaliknya, energi dapat diubah menjadi materi.

Lalu ketika Rasulullah shallallahu 'alaihi wassalam menjalani perjalanan Isra' Mi'raj, Rasul juga bertransformasi dari wujud yang mempunyai massa menjadi makhluk cahaya sebagai bentuk energi. Fenomena seperti ini dapat diajukan untuk memenuhi teori Relativitas, di mana sesuatu yang bergerak dengan kecepatan cahaya atau mendekati kecepatan cahaya maka akan bertambah massanya. Massa suatu benda atau makhluk akan menjadi tak terhingga jika berubah dari keadaan diam menjadi bergerak dengan kecepatan cahaya. Kondisi yang seperti ini tidak mungkin terjadi pada benda atau makhluk yang memiliki massa, namun dapat terjadi untuk makhluk cahaya.

Lalu tambahan untuk itu bahwa massa benda atau makhluk akan berubah jika kecepatannya berubah. Jika kecepatannya memang sudah setara dengan kecepatan cahaya, massanya tidak akan berubah ketika wujudnya bertranformasi dari cahayaa menjadi massa. Artinya, sebuah benda atau makhluk yang dapat memiliki kecepatan setara dengan kecepatan cahaya jika pada saat awal memang sudah bergerak setara dengan kecepatan cahaya. Suatu makhluk cahaya yang sedang bergerak dengan kecepatan cahaya kemudian bertransformasi menjadi makhluk yang memiliki massa, maka kecepatan tetap setara dengan kecepatan cahaya. Jadi, suatu sunnatullah jika Rasulullah shallallahu 'alaihi wassalam menjalani peristiwa Isra' Mi'raj dengan badannya. Jika menganalisis lebih lanjut dalam surah AnNajm ayat 16 dan 17, dapat disimpulkan bahwa Rasulullah berada di Sidratul Muntaha pada peristiwa Mi'raj dengan badannya. Rasulullah dikatakan "melihat" di 
Sidratul Muntaha yang berarti berada di sana dengan badannya dan bukan hanya berupa ruh. ${ }^{18}$

"(Muhammad melihat Jibril) ketika Sidratul Muntaha diliputi oleh sesuatu yang meliputinya, penglihatannya (Muhammad) tidak menyimpang dari yang dilihatnya itu dan tidak (pula) melampauinya." (QS. An Najm : 16-17)

Setelah membahas sedikit mengenai peristiwa Isra' Mi'raj dalam perspektif ilmu fisika, kita dapat menduga sementara bahwa peristiwa maha dahsyat ini akan lebih mengerucut pada ilmu fisika modern dengan tema Relativitas. Berikut akan dijelaskan terlebih dahulu secara umum mengenai konsep Relativitas Einstein dan bagaimana hubungannya dengan peristiwa Isra' Mi'raj. Secara umum, konsep relativitas adalah sebagai berikut :

a) Teori relativitas khusus Einstein tingkah laku benda yang terlokalisasi dalam kerangka acuan inersia, umumnya hanya berlaku pada kecepatan yang mendekati cahaya.

b) Transforazi Lorentz adalah persamaan transformasi yang digunakan untuk menghitung perubahan koordinat benda pada kasus relativitas khusus.

c) Teori Relativitas umum Einstein yaoutu teori yang lebih luas, dengan memasukkan gravitasi sebagai fenomena geometris dalam sistem koordinat ruang dan waktu yang melengkung, juga dimasukkan kerangka acuan non inersia (misalnya : percepatan).

d) Prinsip relativitas fundamental

Jadi, relativitas itu mencakup tranformasi sederhana di antara benda yang bergerak dan seorang pengamat pada kerangka acuan yang lain (inersia). Ilustrasinya, jika anda berjalan di dalam kereta yang bergerak, dan ada seseorang yang diam di luar kereta memperhatikan anda, maka kecepatan anda relatif terhadap pengamat

\footnotetext{
${ }^{18}$ Sani, Abdullah Ridwan. Sains berbasis Al-Qur'an. (Jakarta: PT. Bumi Aksara, 2015), hal. $26-28$. 
adalah total dari kecepatan anda bergerak relatif terhadap kereta dengan kecepatan kereta relatif terhadapa pengamat. Jika anda berada dalam kerangka acuan diam, dan kereta (dan seseorang yg duduk di dalam kereta) berada dalam kerangka acuan lain, maka pengamat adalah orang yang duduk dalam kereta tersebut.Postulat Einstein:

1) Prinsip relativitas (postulat pertama) yaitu hukum-hukum fisika adalah sama untuk setiap acuan.

2) Prinsip kekonstanan kecepatan cahaya (postulat kedua) yaitu cahaya dapat merambat dalam vakum (misalnya, ruang bebas), kecepatan cahaya dinotasikan dengan c, yang konstan terhadap gerka benda yang memiliki radiasi.

Pada dasarnya postulat kedua adalah berasal dari gabungan dua postulat, bukan dari postulat kedua itu sendiri. Pada postulat pertama lebih masuk akal, dan postulat kedua merupakan revolusi besar bagi ilmu fisika. Postulat kedua, adalah sebuah konsekuensi dari foton yang tak bermassa bergerak dengan kecepatan c pada ruang hampa. Eter tidak lagi memiliki peran khusus sebagai kerangka acuan inersia "mutlak" alam semesta, jadi eter secara kualitatif tidak berguna dalam relativitas khusus.

Lalu Einstein menggabungkan persamaan Maxwell untuk listrik dan magnet dengan gerak elektron yang bergerak mendekati kecepatan cahaya. Lalu Einstein menghasilkan transformasi koordinat baru, yang dinamakan transformasi Lorentz, antara kerangka acuan inersia. ${ }^{19}$ Untuk kecepatan cahaya, menghasilkan nilai yang berbeda pada model klasik. Relativitas pun juga mengasilkan efek, dimana di antara efek tersebut terbukti dapat menjelaskan secara ilmiah mengenai peristiwa Isra' dan Mi'raj. yaitu disebutkan sebagai berikut.

1) Dilatasi waktu (Paradoks kembar)

2) Transformasi kecepatan

${ }^{19}$ Halliday, Resnick, dkk. Fisika Dasar Jilid III. (Jakarta: Erlangga, 2010), hal. 15. 
3) Efek doppler relativistik

4) Momentum relativistik

5) Energi kinetik relativistik

6) Massa relativistik

7) Energi total relativistik

Kemudian, pada bagian mana kah teori relativitas berperan dalam menjelaskan peristiwa Isra' dan Mi'raj secara ilmiah, dimulai dari perjalanan Isra' Rasulullah shallallahu 'alaihi wassalam.

1) Bertubuh Cahaya

Rasulullah melakukan perjalanan Isra' didampingi malaikat Jibril dengan mengendarai Buraq perjalanan dari Masjidil Haram di Mekkah ke Masjidil Aqsa dengan kecepatan melebihi kecepatan cahaya yaitu sekitar $300.000 \mathrm{~km}$ per detik.Jika Buraq adalah makhluk hidup yang kecepatannya bisa melebihi kecepatan cahaya, sehingga Rasul dan Jibril sampai pada Masjidil Aqsa di Palestina yang berjarak kurang lebih 1.500 kilometer hanya ditempuh dalam waktu 1/200 detik.

Pada abad 19 Albert Einstein mengungkapkan bahwa kecepatan tertinggi di alam semesta yaitu kecepatan cahaya. Dari sinilah muncul pemahaman mengenai fisika modern. Dalam fisika modern diartikan bahwa kecepatan cahaya dapat dilakukan oleh sesuatu yang sangat ringan bahkan hampir tidak mempunyai massa. Hanya foton lah yang merupakan kuantum penyusun cahaya yang dapat melakukan itu. Bahkan elektron pun yang massa nya hampir mendekati nol tidak dapat melakukan kecepatan setinggi itu.

Nabi shallallahu 'alaihi wassalam yang bukan merupakan makhluk cahaya melakukan kecepatan setinggi kecepatan cahaya. Bagi malaikat Jibril dan Buraq tidak jadi masalah, karena badan mereka tersusun dari foton-foton penyusun cahaya 
sehingga dapat dengan mudah melakukannya. Namun, tubuh Nabi shallallahu 'alaihi wassalam badannya tersusun oleh satuansatuan terkecil penyusun tubuh yaitu sel. Jumlah selnya pun sekitar 390 milyar. Dari sel-sel itu tersusun menjadi jaringan, organ, dan sistem organ. Selain itu terdapat molekul-molekul berupa $\mathrm{H}_{2} \mathrm{O}, \mathrm{O}_{2}$, asam amino, proton, neutron, dan elektron.Seluruh bagian-bagian penyusun itu bergandengan satu sama lain dengan menggunakan energi ikat, supaya tidak tercerai berai. Partikel-partikel sub atomik bergandengan membentuk atom.Atom-atombergandenganmembentuk molekul.

Demikian pula berbagai jenis molekul bergandengan membentuk sel-sel tubuh dan seluruh organ. Dan kemudian organ-organ itu berkolaborasi membentuk badan kita.

Karena manusia memiliki bobot, jangankan untuk dipercepat dengan kecepatan setingkat kecepatan cahaya. Dengan percepatan beberapa kali gravitasi bumi (G) saja, sudah akan mengalami kendala serius, bahkan bisa meninggal dunia. ${ }^{20}$ Jika demikian, Nabi Muhammad shallallahu 'alaihi wassalam juga manusia biasa tidak akan bisa bertahan dengan kecepatan setinggi itu. Memang secara ilmiah sulit untuk mengatakan bahwa Nabimelakukan perjalanan tersebut dengan badan badannya yang normal. Beliau tidak akan bisa bergerak sekencang malaikat Jibril dan Buraq karena badannya memang bukan terbuat dari cahaya. Tetapi dalam fisika modern semua ini dapat teratasi yaitu dengan penjelasan reaksi Annihilasi.

Annihilasi yaitu proses rekontruksi sebuah materi menjadi sebuah gelombang. Ini dapat terjadi karena dalam setiap materi (zat) terdapat anti materi yang apabila direaksikan, keduanya akan

${ }^{20}$ Agus Mustofa. Terpesona di Sidratul Muntaha. (Surabaya: Padma, 2006), hal. 28. 
menghilang dan berubah menjadi seberkas cahaya atau sinar gama.

Hal ini telah dibuktikan di laboratorium nuklirbahwa jika ada partikel proton dipertemukan dengan antiproton, atau elektron dengan positron sebagai antielektronnya, maka kedua pasangan partikel tersebut akan lenyap dan memunculkan dua berkas foton sinar gamma. Energi yang dihasilkan oleh annihilasi elektron dan positron sebesar 0,511 MeV (Mega Electron Volt), sedangkan annihlasi proton menghasilkan energi sebesar $938 \mathrm{MeV}$. Kondisi sebaliknya juga dapat terjadi atau bisa disebut reversibel, yakni jika ada dua berkas foton dengan energi yang bersesuaian saling bertumbukkan, sinar tersebut akan lenyap dan menjadi dua pasangan partikel yang setara nilai energi sinar gammanya. Hal ini menunjukkan bahwa materi dapat diubah menjadi energi dengan cara tertentu dan energi dapat diubah menjadi materi. ${ }^{21}$

Kemungkinan hal ini terjadi sesaat setelah Jibril membersihkan hati Nabi SAW dengan air zam-zam. Hati merupakan pusat dari segala energi pada manusia. Segala perubahan individu dapat diketahui dengan melihat frekuensi hatinya. Dengan "mereaksikan" hati diharapkan ada perubahan karena hati merupakan pusat sistem energi. Dengan segala kehendak-Nya Allah SWT menyuruh Jibril agar "memanipulasi" sistem energi yang ada pada tubuh Nabi SAW. Maka dalam sekejap tubuh material beliau diubah menjadi cahaya dengan reaksi annihilasi. Dan dapat melakukan perjalanan bersama Jibril dengan mengendarai Buraq dengan wujud yang berbeda, yaitu menjadi wujud cahaya.

2) Dilatasi waktu

\footnotetext{
${ }^{21}$ Sani, Abdullah Ridwan. Sains berbasis Al - Qur'an. (Jakarta: PT. Bumi Aksara, 2015), hal. 238. 
"Dari Allah, yang mempunyai tempat-tempat naik. Malaikatmalaikat dan Jibril naik kepada Tuhan dalam sehari yang kadarnya lima puluh ribu tahun." (Q.S Al-Ma'arij : 3-4)

Ayat diatas menerangkan tentang konsep dilatasi waktu sebagaimana yang dikemukakan oleh Albert Einstein dalam teori relativitasnya. Teori Relativitas membahas mengenai Struktur Ruang dan Waktu serta mengenai hal hal yang berhubungan dengan Gravitasi. Teori relativitas terdiri dari dua teori fisika, relativitas umum dan relativitas khusus. Teori relativitas khusus menggambarkan perilaku ruang dan waktu dari perspektif pengamat yang bergerak relatif terhadap satu sama lain, dan fenomena terkait. Tetapi yang akan penulis bahas yaitu tentang relativitas khusus dan efeknya yang disebut dilatasi waktu (dari bahasa Latin: dilatare "tersebar", “delay”). Dalam teori relativitas khusus, Einstein mengemukakan bahwa perbandingan nilai kecepatan suatu benda dengan kecepatan cahaya, akan berpengaruh pada keadaan benda tersebut. Semakin dekat nilai kecepatan suatu benda (v) dengan kecepatan cahaya (c), semakin besar pula efek yang dialaminya $\left(t^{\prime}\right)$ perlambatan waktu. Hingga ketika kecepatan benda menyamai kecepatan cahaya $(v=c)$, benda itu pun sampai pada satu keadaan nol. Demikian, namun jika kecepatan benda dapat melampaui kecepatan cahaya $(\mathrm{v}>\mathrm{c})$, keadaan pun berubah. Efek yang dialami bukan lagi perlambatan waktu, namun sebaliknya waktu menjadi mundur (-t'). ${ }^{22}$

Dalam ilustrasi nya fenomena ini sebagaimana yang dikenal dengan paradoks anak kembar. Dua saudara kembar yang diberi namaSam danSally. Sam tinggal di Bumi dan Sally terbang keluar angkasa ke sebuah planet di tata surya yang jauh dengan kecepatan cahaya dan kembali ke bumi dengan kecepatan yang sama. Setelah mereka bertemu kembali dibumi ternyata umur

${ }^{22}$ Halliday, Resnick, dkk. Fisika Dasar Jilid III.(Jakarta: Erlangga, 2010), hal. 7 10. 
Sallylebih muda daripada umurSamyang tetap tinggal dibumi, disebabkan si traveler Sam mengalami phenomenon time dilation atau fenomena dilatasi waktu dalam perjalanannya.

Lalu hubungannya dengan peristiwa Isra' sebagaimana yang kita ketahui, Nabi SAW beserta Jibril dengan mengendarai Buraq melakukan perjalanan Isra dengan kecepatan 300.000 km/detik dari Masjidil Haram ke Masjidil Aqsha yang berjarak $1500 \mathrm{~km}$. Berarti mereka melakukan perjalanan itu hanya dengan 0,005 detik. Hal itu mungkin saja terjadi mengingat badan beliau yang sudah diubah menjadi cahaya dan dalam perjalanannya mengalami dilatasi waktu. Sehingga dapat melakukannya dalam sekejap mata.

Setelah selesai dengan perjalanan yang pertama, yaitu perjalanan Isra'. Nabi Muhammad shallallahu wa'alaihi wassalam beserta Jibril melanjutkannya kembali dengan perjalanan Mi'raj. Perjalanan Mi'raj ini tidak memakai lagi konsep relativitas khusus seperti pada perjalanan pertama. Setelah mereka tiba di Masjidil Aqsha, badan Nabi SAW tidak lagi berbadan cahaya tetapi sudah kembali dalam bentuk materinya. Hal ini sama dengan konsep teleportasi serta pada perjalanan Mi'raj ini kita gunakan pendekatan perjalanan dimensional. Fenomena perpindahan lokasi jarak jauh atau biasa disebut teleportasi mungkin belum ditemukan secara ilmiah pada saat ini, namun telah diterangkan dalam AlQur'an dalam Surah An Naml ayat 40 :

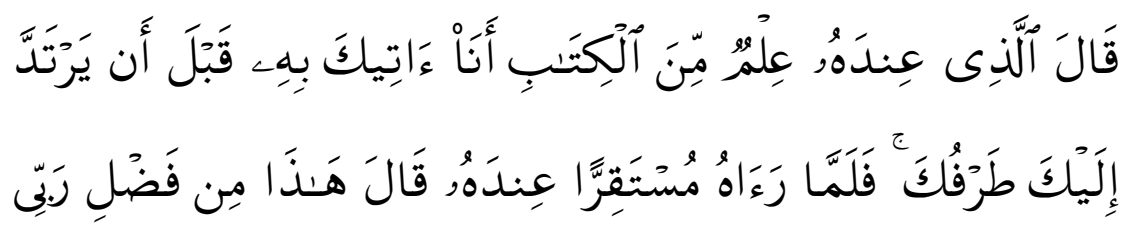




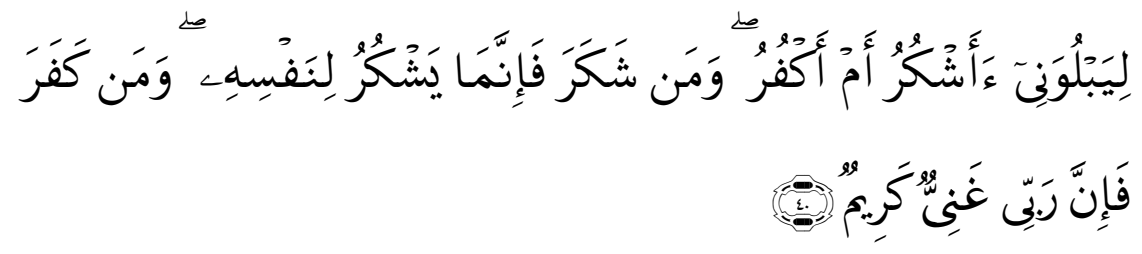

Seorang yang mempunyai ilmu dari Kitab (Taurat dan Zabur) berkata, "Aku akan membawa singgasana itu kepadamu sebelum matamu berkedip." Maka tatkala Sulaiman melihat singgasana itu terletak dihadapannya, ia pun berkata, "Ini termasuk karunia Tuhanku untuk mencoba aku apakah aku bersyukur atau mengingkari (atas nikmatNya ). Dan barangsiapa yang bersyukur untuk (kebaikan) dirinya sendiri dan barangsiapa yang ingkar, maka sesungguhnya Tuhanku Maha Kaya lagi Maha Mulia.” (QS. An Naml : 40)

Secara garis besar bahwa Nabi Muhammad shallallahu 'alaihi wasslam melakukan Mi'raj ini dengan menembus langit pertama yang berdimensi 3 hingga langit ketujuh yang berdimensi 9. Kondisi Nabi sama dengan bayang-bayang yang berada pada tembok yang ingin melepaskan diri ke dunia ruang. Ha itu terjadi karena untuk menembus dimensi yang lebih tinggi diperlukan bantuan makhluk yang berada pada dimensi-dimensi itu. ${ }^{23}$ Mengingat kehadiran Malaikat Jibril yang merupakan makhluk langit ke tujuh yang berdimensi 9. Allah SWT sengaja mengutus Jibril untuk membantu Nabi SAW karena perjalanan ini bukan atas kemauan Nabi SAW melainkan kehendak-Nya.

Isra' dan Mi'raj tidak mungkin dapat dijelaskan secara eksak dan tuntas, tetapi penjelasan dengan teori relativitas dan dimensi ini sudah memberi penjelasan yang memadai. Hal yang paling penting memang bukan tuntasnya penjelasan, melainkan pesan ilmiah yang tersirat didalamnya. Manusia hanya bisa menduga-duga dengan ilmu yang dipelajarinya, selebihnya hanya Allah Yang Maha Mengetahui. Wallahu a 'lam bisshowab.

${ }^{23}$ Purwanto, Agus.2008 . Ayat-ayat Semesta. (Bandung : Mizan Media Utama), hal. 114. 


\section{Kesimpulan}

Isra dan Mi'raj merupakan dua peristiwa yang berbeda hanya saja terpisah menjadi peristiwa Isra' dan peristiwa Mi'raj yang terjadi secara bersamaan dalam satu malam. Isra adalah perjalanan Nabi Muhammad SAW bersama Jibril dari Masjidil Haram ke Masjidil Aqsha dengan mengendarai buraq. Sedangkan Mi'raj adalah diangkatnya Nabi bersama Jibril dari bumi (Masjidil Aqsha) naik ke langit ke tujuh hingga Sidratul Muntaha dengan mengarungi dimensi ruang dan waktu.

Sejarah fisika dimulai pada tahun sekitar 2400 SM. Terbagi kepada empat periode, yaitu periode pertama, periode kedua, periode ketiga (fisika klasik), dan periode keempat (fisika modern). Fisika modern lahir untuk menjelaskan beberapa fenomena yang tidak bisa di jelaskan oleh fisika klasik, Salah satunya yaitu tentang kecepatan cahaya (relativitas) yang dipelopori oleh Albert Einstein pada abad ke 19.

Perjalanan Isra' Nabi Muhmmad shallallahu 'alaihi wassalam dimulai dengan pengubahan badan Nabi menjadi badan cahaya, yang dalam fisika modern dikenal dengan reaksi Annihilasi. Lalu perjalanan dilanjutkan dengan kecepatan melebihi kecepatan cahaya sehingga Nabi SAW, Jibril, dan Buraq dapat sampai di Masjidil Aqsha dengan sekejap mata.

Perjalanan Mi'raj Nabi Muhammad shallallahu 'alaihi wassalam merupakan perjalanan lintas dimensi dengan menembus batas-batas langit dari langit pertama hingga langit ke tujuh.

\section{E. Daftar Pustaka}

Al Quran Al Karim, Jakarta Penerbit C.V. Pustaka Amani, 2006.

Halliday, Resnick.dkk. Fisika Dasar Jilid III. Jakarta: Erlangga, 2010. 
Katsir, Ibnu. Sejarah Nabi Muhammad. Solo: At - Tibyan, 2004.

Muhammad Al-Ghazali, Sejarah Perjalanan Hidup Muhammad, Yogyakarta: Mitra Pustaka,Cet.3, 2005.

Mustofa, Agus. Terpesona di Sidratul Muntaha. Surabaya: Padma, 2006.

Purwanto, Agus. Ayat - Ayat Semesta. Bandung: Mizan Media Utama, 2008.

Sani, Abdullah Ridwan. Sains Berbasis Al-Qur'an. Jakarta: PT. BumiAksara, 2015.

Shafiyyurrahman Al-Mubarakfury, Ar-Rakhiq Al-Makhtum, AlManshurah: Dar Al-Wafa, 2002.

Yunasril, Ali. Ensiklopedia Islam. Jakarta: Ichtiear Baru Van Hoeve, 2005.

Syaikh Shafiyurahman Al-Mubarakfuri, Sirah Nabi, Bandung: PT Mizan Pustaka, 2012

\section{$\underline{\text { Web }}$}

Anonim. Periode Sejarah Fisika Menuju Era Modern. onlineTersedia:http://nisyadiaries28.blogspot.com/2013/04/4periode-sejarah-fisika-menuju-era.html. (1 Januari 2018) 